\title{
THE ALLOMETRY OF BIOMASS ALLOCATION TO VARIOUS ORGANS IN COTTON (Gossypium hirsutum L.) DEPENDING GROWTH PERIOD
}

\author{
GAO, X. - TANG, F.* \\ Key Laboratory of Crop Physiology, Ecology and Genetic Breeding, College of Agronomy, \\ Ministry of Education, Jiangxi Agricultural University, Nanchang 330045, China \\ *Corresponding author \\ e-mail: fytangcau@163.com \\ (Received 29 $9^{\text {th }}$ Nov 2020; accepted $27^{\text {th }}$ Jan 2021)
}

\begin{abstract}
Biomass allocation to various components of the cotton plant is an important determinant of lint yield. Two Near-isogenic upland cotton lines 4003-6 and 4003-10 differing in growth period were employed to explore ontogenetic allometric relationships between various structures of field-grown cotton plants during reproduction using Standardized Major Axis. Compared to the later maturing line (4003-6), the earlier maturing line (4003-10) allocated i) proportionally more biomass to reproductive structures at a given vegetative biomass, and initiated reproduction at smaller plant sizes; ii) proportionally less biomass to roots at a given aerial biomass at early reproduction stage but this process was reversed at late reproduction stage; iii) proportionally less biomass to branches at a given stem biomass at late reproduction stage. It is concluded that the earlier maturing cotton line was characterized by deficient root growth at early reproduction stage and limited branch growth at late reproduction stage relative to later maturing line.
\end{abstract}

Keywords: root-shoot relationship, reproductive biomass, vegetative biomass, Standardized Major Axis, early maturing

\section{Introduction}

Upland cotton (Gossypium hirsutum L.) has an indeterminate growth habit, which leads to the simultaneous production of both vegetative and reproductive structures during considerable period of growing season. Moreover, cotton is exceedingly sensitive to environmental constrains to which it responds mainly by shedding reproductive structures (Oosterhuis and Stewart, 2004). The different organs of cotton take on distinct functions, such as leaves for photosynthesis, roots for uptake of water and nutrient. The growths of these organs depend heavily on the biomass partitioned to them, and in turn affect final lint yield. According to the optimal partitioning theory, environmental constraints usually result in greater biomass allocation to organs under growth limitations (Reynolds and Thornley, 1982; Ploschuk et al., 2005; Luo et al., 2006; Wang and Taub, 2010; Cheng et al., 2015; Luo et al., 2016).

Traditionally, allocation patterns have been defined and calculated as ratios (Weiner et al., 2009). However, allocation in the term of ratios is size-independent, whereas plant allocation is allometric and size-dependent as found in a wide range of plant species (McConnaughay and Coleman, 1999; Weiner, 2004; Otárola et al., 2016; Hill and Roberts, 2017; Chen et al., 2018). Allometric studies indicated that there were strong couplings between various plant components. i.e. between roots and shoots biomass (Niklas, 2005; Yang et al., 2010), between leaf mass and leaf area (Pan et al., 2013), between rate and duration of seed growth (Sadras and Egli, 2008), between leaf size and twig size (Westoby and Wright, 2003). Understanding of allometric 
relationships in crops is of agronomical significance both in developing crop simulation models and in estimating crop parameters which are difficult to measure. For example, the allometric function relating below-ground biomass $\left(M_{B}\right)$ to above-ground biomass $\left(M_{A}\right)$ can be employed to estimate $M_{B}$ from the more easily measured $M_{A}$ (Mokany et al., 2006; Yang et al., 2010; Yang and Luo, 2011). Up to date, allometric analysis primarily has concentrated on wild-born species spread within a certain terrestrial ecosystem. For field-grown crops exposed to man-created environment, the biomass allometry between various parts is poorly understood. Cotton is not the exception.

Earliness is an important consideration in the selection of cultivars for those cotton grown areas with low thermal availability or limited growing season. Short-season cotton cultivars had different reproductive allocation strategies from long-season ones (Bange and Milroy, 2000, 2004). Early cotton genotypes partitioned a greater proportion of biomass to reproductive forms than late genotypes (Pace et al., 1999; Bange and Milroy, 2000), but in another study by Bange and Milroy (2004) who argued that early genotypes did not show a preferential partitioning of dry matter to reproductive structures, and higher rate of partitioning did not necessarily cause early maturity. A majority of previous works dealt with relationships between dry matter production and allocation and cotton maturity in the partitioning-ratio context rather than the allometric view. Moreover, those works were not involved in the relationship between agronomically important traits, such as between $M_{B}$ and $M_{A} . M_{A}$ is commonly equated with plant size deemed as an important determinant to reproductive output (Weiner et al., 2009). Presently, it remains obscure how cotton allocates its resources to organs or functions during its ontogenetic development. The process involves investment trade-off because resources allocated to one organ are not available to other organs (Guo et al., 2012). In the present study, we have hypothesized that the allometric patterns between various components of cotton plants vary with the time to reproductive maturity. In an attempt to test the hypothesis, two Near-isogenic cotton lines 4003-6 and 4003-10 with the same genetic background but differing in growth period were employed to explore allometric relationships i) between reproductive and vegetative biomasses; ii) between above- and below ground biomasses; iii) between paired and physically linked organs (stem vs branch, branch vs leaf, carpel vs seedcotton). Knowledge of these allometric relationships would help establish optimal management practices to promote cotton growth and maximize lint yield.

\section{Materials and Methods}

\section{Experimental Design}

The experiment was conducted at the experimental station of Jiangxi Agricultural University (JXAU), Nanchang, China in 2017 and 2018. Two Near-isogenic upland cotton lines 4003-6 and 4003-10 were employed to examine biomass allocation among various plant structures and functions. 4003-10 was derived from a variant plantlet of 4003-6 and has been developed after successive generations of self-pollination in an attempt to reach homozygosity. They have the same genetic background and perform similarly in a wide range of attributes but differing in growth period with 4003-6 being a middle maturing line and 4003-10 being an early maturing line. The soil type was clay, mixed, thermic, Typic alfisols (udalfs; FAO luvisol) with a slightly acid pH of 5.6. The upper $20 \mathrm{~cm}$ soil layer contained 23.0 and $26.2 \mathrm{~g} \mathrm{~kg}^{-1}$ organic matter, 1.3 and $1.5 \mathrm{~g} \mathrm{~kg}^{-1}$ total $\mathrm{N}, 85.8$ and $92.4 \mathrm{~g} \mathrm{~kg}^{-1}$ available $\mathrm{N}, 58.6$ and $72.2 \mathrm{~g} \mathrm{~kg}^{-1}$ available $\mathrm{P}$, and 
170.4 and $190.7 \mathrm{~g} \mathrm{~kg}^{-1}$ available $\mathrm{K}$ in 2017 and 2018, respectively. Seeds were sowed in a nursery bed on 15 April 2017 and 26 April 2018, and seedlings were transplanted into the experimental field on 14 May 2017 and 17 May 2018, respectively. Plots were arranged in a randomized complete block design with three replications. Each plot contained six rows spaced $1 \mathrm{~m}$ apart and $9.3 \mathrm{~m}$ long with a $0.3 \mathrm{~m}$ of interplant distance. The four centered rows were used for plant sampling and the remaining outside rows were used to determine yield. A total of $240 \mathrm{~kg} \mathrm{~N} \mathrm{ha}^{-1}, 108 \mathrm{~kg} \mathrm{P} \mathrm{ha}^{-1}$ and $225 \mathrm{~kg} \mathrm{~K} \mathrm{ha}^{-1}$ was incorporated into fields. The $\mathrm{P}$ and $\mathrm{K}$ fertilizers were split applied in 1:1 ratio prior to planting and at first flowering, respectively. The $\mathrm{N}$ fertilizer was distributed in 1:2:1 ratio prior to planting, first flowering and peak flowering, respectively. Management practices including irrigation, insect and weed control were performed as needed during each of the growing seasons.

\section{Sampling Procedure and Data Collection}

Seven or eight samplings were taken at two-week intervals from 77 to 161 days after planting (DAP) in 2017, and 64 to 162 DAP in 2018. The sampling commenced at the squaring stage when $50 \%$ of plants produced flower buds (squares) for the middle maturing line (4003-6) and terminated until peak boll opening. Two lines were sampled on the same date, not by the exact growth stage. Within a plot, selected plants were located far apart from one another, to ensure that the growth of remaining plants was not affected by the earlier sampling of other plants. Three individual plants in each of plots were uprooted and washed free of soil, and then transferred in an icebox to the lab where they were separated into six parts: roots, main stems, branches, leaves, reproductive parts. Subsamples were oven-dried at $105^{\circ} \mathrm{C}$ for $0.5 \mathrm{~h}$ and then at $60{ }^{\circ} \mathrm{C}$ to a constant weight. At the cotton maturation stage, a 50-bolls sample was collected from the unsampled rows of each plot for determining boll weight and lint percentage. All plots were hand-harvested three or four times before frost, and lint yields were determined by weighing seedcotton per plot and multiplying by lint percentage and expressed as kilogram per hectare $(\mathrm{kg} / \mathrm{ha})$. The growth period was termed as a period of planting date to cotton maturity (60\% of bolls open) (Bange and Milroy, 2000).

\section{Data Analysis}

The data of cotton lint yield and yield components were subjected to IndependentSamples $t$-test. Means were separated at the probability level of 0.05 . The other raw data were $\log _{10}$ transformed to fit the assumption of normality and homogeneity which were certified using Kolmogorov-Smirnov and Levene's tests, respectively. Standardized Major Axis regression and correlation analyses were applied to the $\log _{10}$ transformed data. Correlation analysis showed there were significant high log-log relationships between paired variables. The log-log linear function can be expressed as $\log _{10} Y=a \log _{10} X+b$, which is the $\log _{10}$ transformed version of the classical power function $Y=b X^{a}$, where $a$ is the scaling exponent (slope) and $b$ is the allometric constant ( $Y$-intercept). A likelihood ratio method was employed to test for homogeneity of slopes and calculation of common slopes (Warton and Weber, 2002). Elevation (i.e. $Y$-intercept) differences between two linear regression models with the common slope were tested by Wald statistic. The slope and $Y$-intercept were determined using the software package "Standardized Major Axis Tests and Routines version 2.0" (Falster et al., 2006). All figures were produced by Origin 8.5. 


\section{Results}

\section{Yield, Yield Components and Growth Period}

4003-6 had a longer growth period than 4003-10 with the former being around two weeks longer than the latter (Table 1). 4003-10 initiated flowering about one week earlier than 4003-6. Higher seedcotton yield and lint yield were observed in 4003-6 than in $4003-10$ in 2018 , but not significant in 2017. 4003-6 exhibited a higher lint percentage than 4003-10, but no difference was found in bolls per plant across two years.

Table 1. Cotton yield, yield components and growth period in lines 4003-10 and 4003-6 across 2017 to 2018

\begin{tabular}{c|c|c|c|c|c|c|c}
\hline Year & Genotype & $\begin{array}{c}\text { Bolls } \\
\left(\text { plant }^{-1}\right)\end{array}$ & $\begin{array}{c}\text { Boll } \\
\text { size(g) }\end{array}$ & $\begin{array}{c}\text { Lint percentage } \\
(\boldsymbol{\%})\end{array}$ & Seedcotton & $\begin{array}{c}\text { Lint yield } \\
(\mathbf{k g})\end{array}$ & $\begin{array}{c}\text { Growth } \\
\text { period (d) }\end{array}$ \\
\hline \multirow{2}{*}{2017} & $4003-10$ & 38.1 & 4.4 & 37.2 & 2658.0 & 991.0 & 116 \\
& $4003-6$ & 39.7 & 4.7 & $40.0^{* *}$ & 2661.4 & 1063.6 & 130 \\
& $P>F^{\dagger}$ & 0.536 & 0.211 & 0.002 & 0.996 & 0.790 & \\
\hline \multirow{2}{*}{2018} & $4003-10$ & 30.4 & 3.9 & 39.0 & 2345.9 & 913.7 & 113 \\
& $4003-6$ & 28.5 & 4.6 & $41.2^{* *}$ & $2737.0^{*}$ & $1126.9^{*}$ & 125 \\
& $P>F$ & 0.187 & 0.100 & 0.007 & 0.048 & 0.014 & \\
\hline
\end{tabular}

$\dagger$ t-test was conducted for means between two lines. ${ }^{*}, *$ indicated significantly different at 0.05 and 0.01 level, respectively

\section{Relationships between Reproductive Biomass and Vegetative Biomass}

There was a significant positive relationship between log reproductive biomass $\left(M_{R}\right)$ and $\log$ vegetative biomass $\left(M_{V}\right)$ for each of the lines (Fig. 1). Two lines shared the commonly fitted slopes of $\log M_{R}$ to $\log M_{V}$ relationship at 2.39 in 2017 and at 2.27 in 2018, respectively. The scaling exponents of $M_{R}$ to $M_{V}$ were significantly greater than 1 (lower and upper 95\% confidence intervals CIs equaled 2.24 and 2.54 in 2017, 2.11 and 2.45 in 2018, respectively), indicating larger individuals allocated proportionally more biomass to reproductive structures than to the other structures as reproduction progressed.

Allometric constants ( $Y$-intercept) were negative irrespective of genotypes and years, suggesting there is a minimum size for cotton reproduction. This may be the case because cotton plant must have sufficient resources to build the reproductive support structures before the first boll can be produced. The $Y$-intercept was significantly different between two lines with 4003-10 being greater than 4003-6 $(P<0.001$ for $2017, P<0.014$ for 2018). This result showed that the earlier maturing line tended to have more reproductive biomass at given vegetative biomass.

The $X$-intercept of linear regression on the $M_{R}-M_{V}$ relationship is considered as the threshold size for reproduction (Bonser and Aarssen, 2009). 4003-10 exhibited a smaller threshold size for reproduction than 4003-6 (1.58 versus 1.73 in 2017, and 1.61 versus 1.67 in 2018), which means that earlier maturing line is capable of initiating reproduction at relatively smaller sizes. 


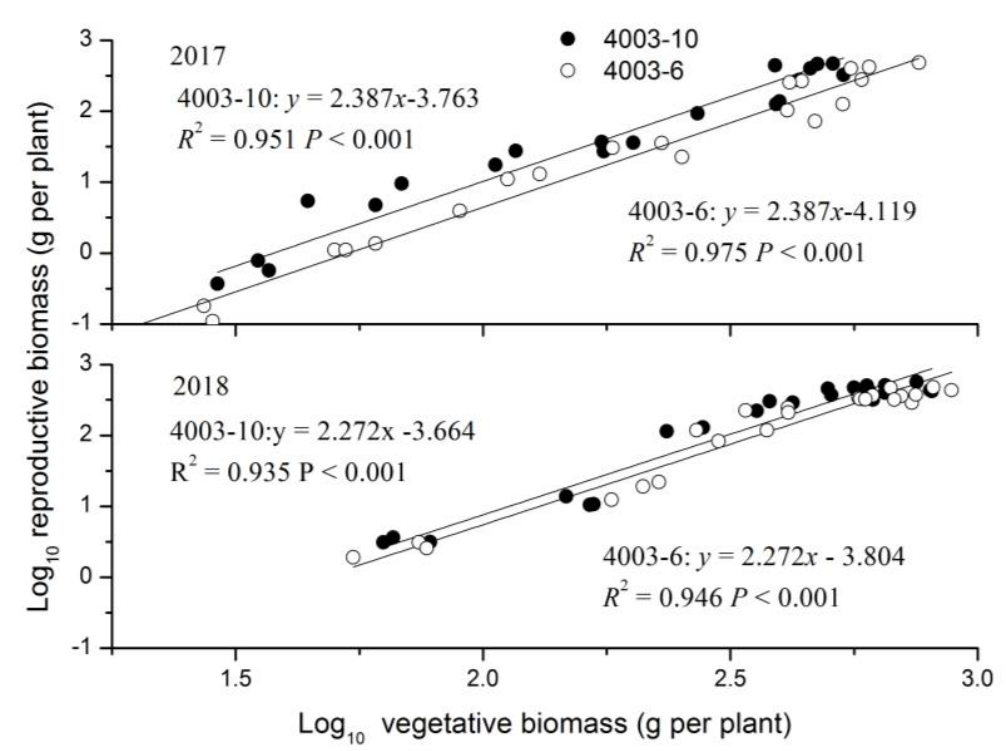

Figure 1. Allometric relationships between reproductive mass and vegetative mass of cotton over two Near-isogenic lines 4003-6 and 4003-10

\section{Relationships between Below-ground Biomass and Above-ground Biomass}

Log above-ground biomass $\left(M_{A}\right)$ was significantly positively correlated with $\log$ below-ground biomass $\left(M_{B}\right)$ for either of two lines (Fig. 2). The regression slope of log $M_{B}$ on $\log M_{A}$ in 4003-10 was significantly > 1 with a $95 \%$ CI of 1.003 to 1.115 in 2017, but $=1$ with a $95 \%$ CI of 0.963 to 1.165 in 2018 , indicating that biomass allocated to roots disproportionately exceeded that to shoots or both increased in the same proportion. The slopes with 4003-6 were significantly < 1 with $95 \%$ CIs of 0.794 to 0.920 in 2017, and of 0.863 to 0.983 in 2018, indicating that a marginal increase in $M_{A}$ caused a proportionally smaller increase in $M_{B}$. The result showed that the scaling relationship between $M_{A}$ and $M_{B}$ varied between cotton genotypes.

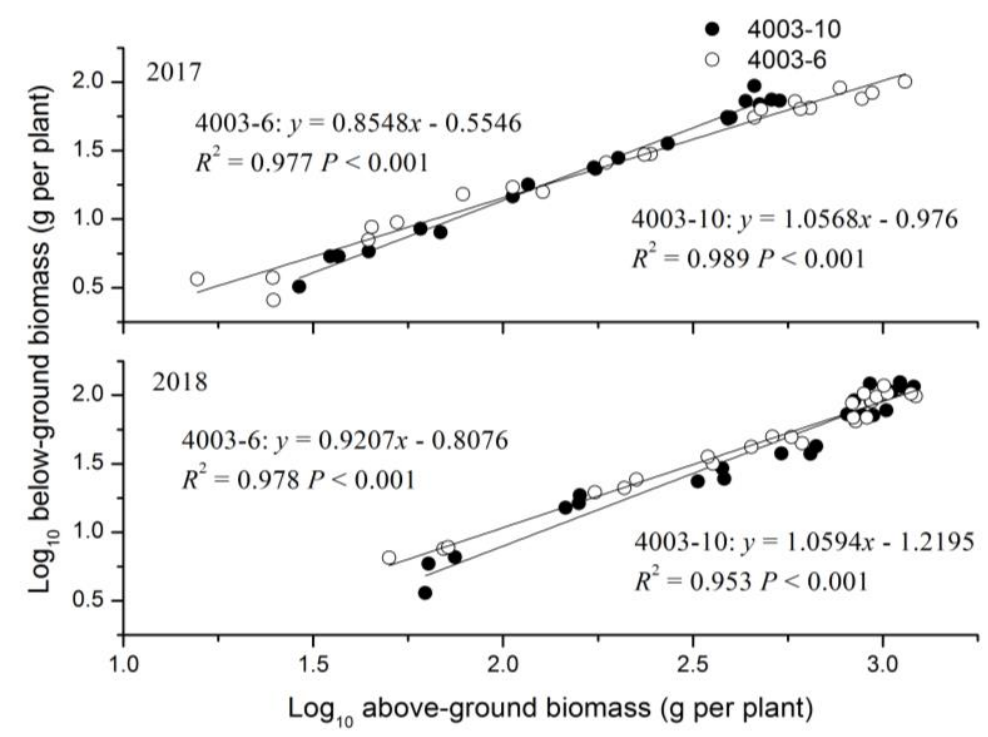

Figure 2. Allometric relationships between below- and above-ground mass of cotton over two Near-isogenic lines 4003-6 and 4003-10 
The $Y$-intercept of the regression of $\log M_{B}-\log M_{A}$ was greater in 4003-6 than in 4003-10 over two years (Fig. 2). Moreover, allometric regression lines of both were crossed (Fig. 2), which means 4003-10 had a smaller $M_{B}$ at a given $M_{A}$ than 4003-6 prior to the cross point and the opposite was true of after the cross point. The combination of the higher slope and the lower $Y$-intercept for the earlier maturing line indicated that it allocates proportionately less biomass to roots at early reproductive growth stage and more at late reproductive growth stage compared with the later maturing line.

\section{Relationships between Branch Biomass and Stem Biomass}

Significant and positive correlations were observed between log stem biomass and $\log$ branch biomass (Fig. 3). The slopes of the log branch biomass to log stem biomass were all above 1 irrespective of genotypes and years, and differed between two lines, indicating cotton allocated proportionally more biomass to branches than to main stem after reproduction initiation (Fig. 3). 4003-6 had larger slopes and smaller $Y$-intercept compared to 4003-10 over two years, which means the former exhibited a smaller branch biomass at a given stem biomass at early reproductive stage, but the reversed appeared as reproduction progressed.

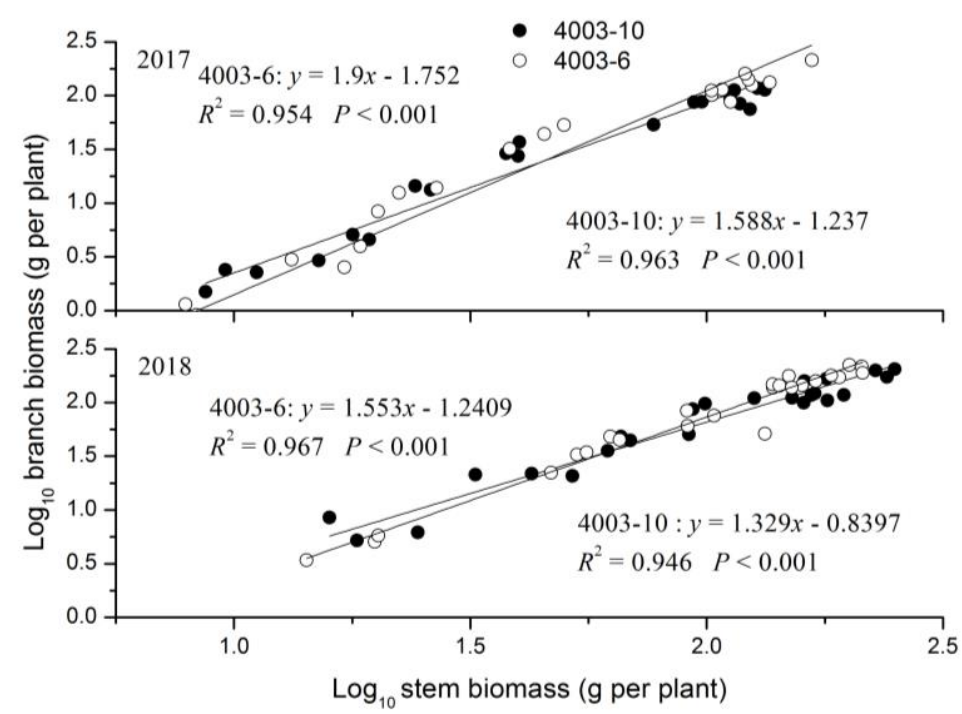

Figure 3. Allometric relationships between branch mass and stem mass of cotton over two Near-isogenic lines 4003-6 and 4003-10

\section{Relations between Leaf Biomass and Branch Biomass}

Log branch biomass correlated positively with log leaf biomass (Fig. 4). The slopes of the log leaf biomass to branch biomass were all below 1 regardless of genotypes and years, indicating cotton allocated proportionally less biomass to leaves than to branches during reproduction period. Greater slope and smaller elevation were recorded in 4003-10 relative to 4003-6 in 2017, but two lines shared a common slope at 0.5413 with no difference in $Y$-intercepts in 2018 (Fig. 4). 


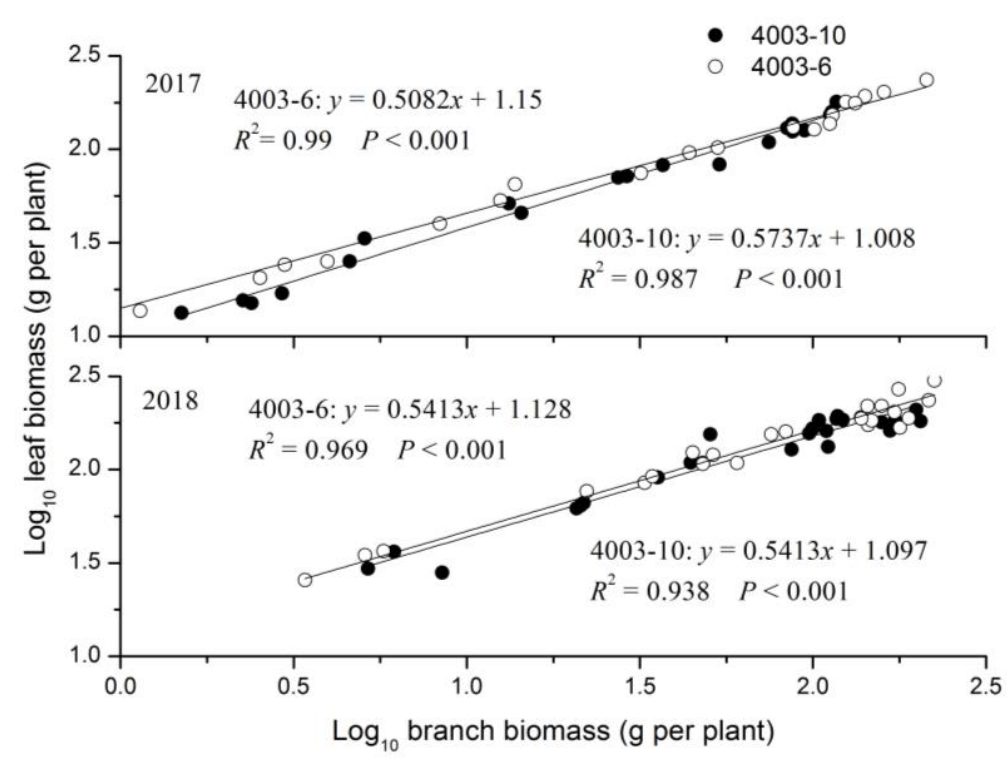

Figure 4. Allometric relationships between leaf mass and branch mass of cotton over two Nearisogenic lines 4003-6 and 4003-10

\section{Relations between Boll (fibers plus seeds) Biomass and Carpel Biomass}

There was a positive and significant correlation between log boll biomass and log carpel biomass (Fig. 5). The slope of log boll biomass to log carpel biomass was greater than 1 over two lines across two years, indicating cotton partitioned proportionally more biomass to fibers and seeds than to carpels with advancing boll development (Fig. 5). Two lines shared common slopes and no significant difference in elevation was observed.

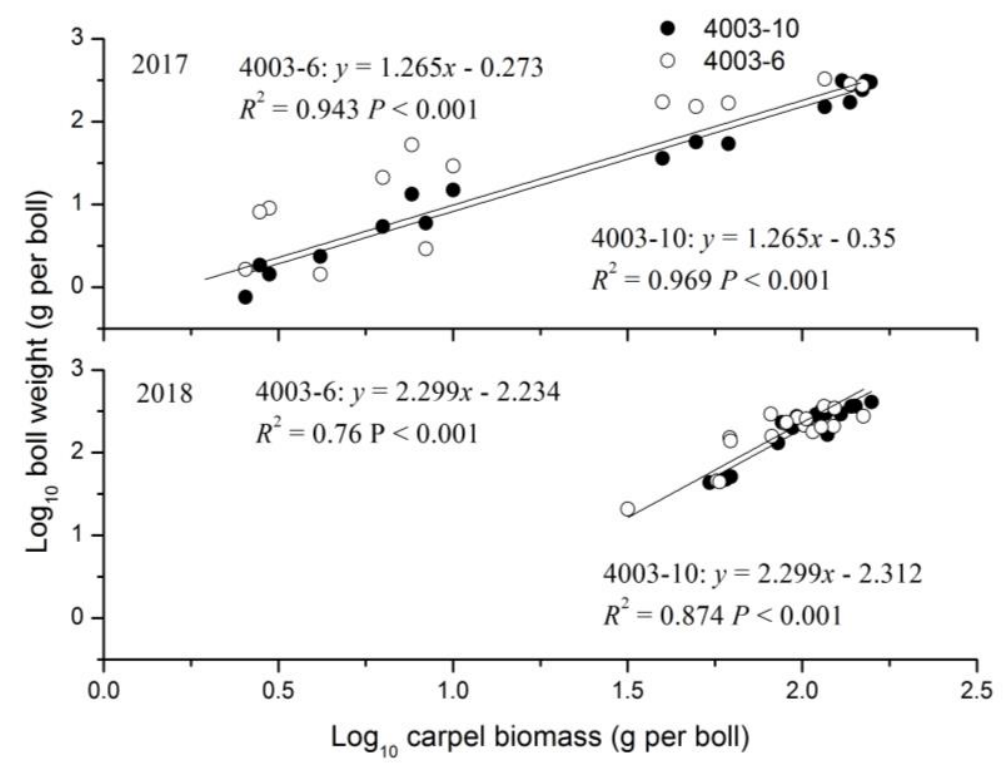

Figure 5. Allometric relationships between boll mass and carpel mass of cotton over two Nearisogenic lines 4003-6 and 4003-10 


\section{Discussion}

Allocation pattern with field-grown crops was largely investigated in the view of ratios. The method did not take into account plant size. With plant size being one of the most important factors affecting reproductive output, allocation patterns would be better understood by analyzing and interpreting the allometric relationship between reproductive and vegetative biomass within a population compared with traditional reproductive allocation approach based on ratios (Samson and Werk, 1986; Sugiyama and Bazzaz, 1998; Karlsson and Mendez, 2005).

4003-10 exhibited greater $Y$-intercepts of $\log M_{R}$ to $\log M_{V}$ relationship on the basis of the common slope over two years, indicating the former tended to have proportionally more reproductive biomass at given vegetative biomass. The result is somewhat similar to an early report by Bange and Milroy (2000) that the shorter-season cultivar partitioned significantly more of dry matter increment to reproductive structures than the long-season cultivar during the initial period of boll growth. The difference of $Y$-intercept may be the result of the difference in the growth period, because the shorter lifespan in the earlier maturing cultivar may prompt it to convert proportionally more biomass to reproductive biomass in an effort to complete its life cycle as soon as possible. 4003-10 exhibited a smaller threshold size for reproduction than 4003-6 over two years (Fig. 1), indicating the former can initiate reproduction at smaller sizes than the latter, as consistent with the report of Bange and Milroy (2004) that partitioning to the fruit began earlier in early genotypes. Similar to this, individuals living in adverse environments tend to allocate more of their biomass to reproduction (e.g., seeds) at small sizes compared with ones growing in more benign environments because of a high risk of early death before reproduction (Guo et al., 2012). Environmental adversity is apt to trigger reproduction at relatively small sizes (Bonser and Aarssen, 2009).

Two cotton lines exhibited different scaling relationship between $M_{A}$ and $M_{B}$ from one another across two years (Fig. 2). 4003-6 recorded a slope of $\log M_{A}$ to $\log M_{B}$. regression below 1 over two years, but $\geqq 1$ for 4003 -10. In a pot experiment with five alpine plant species where Luo et al. (2016) observed that the allometry between $M_{A}$ and $M_{B}$ was altered by the $\mathrm{N}: \mathrm{P}$ supply ratio. By contrast, a substantial amount of studies with forest or grassland ecosystems reported that $M_{B}$ scaled nearly isometrically with $M_{A}$ and the scaling relationship changed little with various environmental conditions (Cheng et al., 2015; Niklas, 2005; Yang et al., 2010; Yang and Luo, 2011). The fluctuation in scaling relationships with changing environments was considered as increased individual fitness, which can be a disadvantage for plant production system where optimal population is preferred instead of individual performance (Weiner, 2004). 4003-10 had higher regression slopes but lower $Y$-intercepts than 4003-6 over two years (Fig. 3), which means proportionally less biomass partitioning to 4003-10 roots at early reproduction stage and the reversed at late reproduction stage. Root to shoot ratio is easily affected by environmental conditions (Weiner, 2004). Increased root to shoot ratio in cotton under soil moist deficit was largely due to a significant increase in root biomass with little change in shoot biomass (McMichael and Quisenberry, 1991). Early reproduction in cotton (i.e. squaring) is seen as the most critical phase for the development of roots system. A greater biomass partition to roots in 4003-6 at that stage should contribute to increasing its capacity of taking up water and nutrients at successive stages of development (i.e. flowering and fruiting), which may translate into a higher reproductive output. Contrarily, 4003-10 distributed less dry mass to roots at early reproduction, which may lead to deficient roots growth and 
limited nutrient uptake, and in turn fail to meet the resource requirement for growing boll loading, and thus produce a potential risk of premature. Those resources failing to trigger the initiation of new fruit sits are potentially transported into roots and stored there for the next growth cycle. This maybe the reason that a greater biomass partition to roots at late reproduction for 4003-10 relative to 4003-6. The improvement of root growth with early maturing genotype prior to reproduction initiation is supposed to be a promising strategy for further enhancing cotton yield.

The slopes of log branch biomass to either log stem biomass or log leaf biomass were above 1 irrespective of genotypes and years (Fig. 3, Fig.4), indicating cotton allocated proportionally more biomass to branches than either of stem and leaves after reproduction initiation. More branches potentially grow more fruiting forms which can help to achieve higher yield. It has been well known that sympodials per plant correlates positively with seedcotton yield per plant (Rao and Gopinath, 2013; Majeedano et al., 2014). 4003-6 presented greater slope and smaller $Y$-intercept with regard to the regression relationship of $\log$ branch biomass on log stem biomass, indicating it allocated proportionally more biomass to branches than to stem compared to 4003-10 as reproduction progressed. The result reflects that 4003-6 expressed more vigorous growth potential at late reproduction stage.

Allometric relationships have generally been deemed to be genetically determined, i.e. species- or genotype-specific (Weiner, 2004). On the other hand, allometric patterns varied with environmental and developmental constraints especially in short-lived (annual) ones (Reekie and Bazzaz, 1987; Weiner and Thomas, 1992). Presumably, Cotton is featured by comparatively high plasticity in growth allometry owing to its indeterminate growth habit. Allometric relationships from the present study may apply simply to the cotton population with enough growing season, low plant density and limited soil fertility availability which can create a symmetric competition among individuals (Bazzaz et al., 2005). The allometry of biomass allocation in cotton may be changed with varying plant density and soil fertility levels.

Based on the allocation patterns between $M_{R}$ and $M_{V}$, and between $M_{A}$ and $M_{B}$, it can be concluded that the early maturing genotype experiences greater developmental constraints, e.g. deficient root growth at early developmental stages, and reproduction initiation at smaller sizes, etc. Thus, cultivation practices should be applied to the early genotypes earlier than others aiming to establish well-developed roots and enlarge plant size before reproduction initiation. The alternative managements should prioritize intertillage weeding during seedling through squaring and increasing resources availability to them at early development.

\section{Conclusions}

During reproduction period, the earlier maturing line (4003-10) allocated i) proportionally more biomass to reproductive structures at a given vegetative biomass, and initiated reproduction at smaller plant sizes; ii) proportionally less biomass to roots at a given aerial biomass at early reproduction stage but the reversed at late reproduction stage; iii) proportionally less biomass to branches at a given stem biomass at late reproduction stage. It is suggested that earlier maturing cotton line was characterized by deficient root growth at early reproduction stage and limited branch growth at late reproduction stage relative to later maturing line. It is worth noting that those allometric relationships may apply simply to the cotton population with enough growing season, 
low plant density and limited soil fertility availability which can create a symmetric competition among individuals. The issue deserves further study how the allometry of biomass allocation in cotton responds to varying plant density and soil fertility levels.

Acknowledgments. This study was funded by the National Natural Science Foundation of China (Grand number: 31960385,31560364$)$.

\section{REFERENCES}

[1] Bange, M. P., Milroy, S. P. (2000): Timing of crop maturity in cotton: impact of dry matter production and partitioning. - Field Crops Research 68(2): 143-155.

[2] Bange, M. P., Milroy, S. P. (2004): Growth and dry matter partitioning of diverse cotton genotypes. - Field Crops Research 87(1): 73-87.

[3] Bazzaz, F. A., Ackerly, D. D., Reekie, E. G. (2005): Reproductive allocation in plants. In: Fenner, M. (ed.) Seeds: The Ecology of Regeneration in Plant Communities. Wallingford, UK: CAB International 2000, pp. 1-29.

[4] Bonser, S. P., Aarssen, L. W. (2009): Interpreting reproductive allometry: individual strategies of allocation explain size-dependent reproduction in plant populations. Perspectives in Plant Ecology Evolution and Systematics 11: 31-40.

[5] Chen, G., Hobbie, S. E., Reich, P. B., Yang, Y., Robinson, D. (2018): Allometry of fine roots in forest ecosystems. - Ecology Letter 22(2): 322-331.

[6] Cheng, D., Zhong, Q., Niklas, K. J., Ma, Y., Yang, Y., Zhang, J. (2015): Isometric scaling of above- and below-ground biomass at the individual and community levels in the understorey of a sub-tropical forest. - Annals of Botany http://dx.doi.org/10.1093/aob/mcu238.

[7] Falster, D. S., Warton, D. I., Wright, I. J. (2006): SMATR: Standardized major axis tests and routines, ver 2.0. - http://www.bio.mq.edu.au/ecology/SMATR/.

[8] Guo, H., Weiner, J., Mazer, S. J., Zhao, Z., Du, G., Li, B. (2012): Reproductive allometry in Pedicularis species changes with elevation. - Journal of Ecology 100: 452-458.

[9] Hill, T. D., Roberts, B. J. (2017): Effects of seasonality and environmental gradients on Spartina alterniflora allometry and primary production. - Ecology and Evolution 7: 96769688.

[10] Karlsson, P. S., Mendez, M. (2005): The resource economy of plant reproduction. - In: Reekie, E. G., Bazzaz, F. A. (ed.) Reproductive Allocation in Plants. Burlington, MA: Elsevier Academic Press, pp. 1-49.

[11] Luo, Y., Hui, D., Zhang, D. (2006): Elevated $\mathrm{CO}_{2}$ stimulates net accumulations of carbon and nitrogen in land ecosystems: a meta-analysis. - Ecology 87: 53-63.

[12] Luo, X., Mazer, S. J., Guo, H., Zhang, N., Weiner, J., Hu, S. (2016): Nitrogen: phosphorous supply ratio and allometry in five alpine plant species. - Ecology and Evolution 6(24): 8881-8892.

[13] Majeedano, M. S., Ahsan, M. Z., Soomro, A. W., Panhwar, F. A., Channa, A. R. (2014): Heritability and corrrelations estimates for some yield traits of Gossypium hirsutum L. American Research Thoughts 1(2): 781-790.

[14] McConnaughay, K. D. M., Coleman, J. S. (1999): Biomass allocation in plants: ontogeny or optimality? A test along three resource gradients. - Oecologia 113: 447-455.

[15] McMichael, B. L., Quisenberry, J. E. (1991): Genetic variation for root-shoot relationships among cotton germplasm. - Environmental and Experimental Botany 31(4): 461-470.

[16] Mokany, K., Raison, R. J., Prokushkin, A. S. (2006): Critical analysis of root: shoot ratios in terrestrial biomes. - Global Change Biology 12: 84-96. 
[17] Niklas, K. J. (2005): Modeling below- and above- ground biomass for non-woody and woody plants. - Annals of Botany 95: 315-321.

[18] Oosterhuis, D. M., Stewart, J. M. (2004): Physiological basis of yield and environmental adaptation in cotton. - In: Nguyen, H. T., Blum, A. (ed.) Physiology and Biotechnology Integration for Plant Breeding. - New York: Marcel Dekker Inc., pp. 363-401.

[19] Otárola, M. F., Sazima, M., Solferini, V. N. (2016): Stem and crown allometry in four congeneric species of dioecious tropical trees. - Trees 30(6): 2041-2049.

[20] Pace, P. F., Cralle, H. T., Cothren, J. T., Senseman, S. A. (1999): Photosynthate and dry matter partitioning in short- and long- season cotton cultivars. - Crop Science 39: 10651069.

[21] Pan, S., Liu, C., Zhang, W., Xu, S., Wang, N., Li, Y., Gao, J., Wang, Y., Wang, G. (2013): The scaling relationships between leaf mass and leaf area of vascular plant species change with altitude. - PLoS One 8(10): e76872. http://dx.doi.org/10.1371/journal.pone.0076872.

[22] Ploschuk, E. L., Slafer, G. A., Ravetta, D. A. (2005): Reproductive allocation of biomass and nitrogen in annual and perennial Lesquerella crops. - Annals of Botany 96: 127-135.

[23] Rao, P. J. M., Gopinath, M. (2013): Association analysis of yield and fibre quality characters in upland cotton (Gossypium hirsutum L.). - Australian Journal of Basic and Applied Science 7(8): 787-790.

[24] Reekie, E. G., Bazzaz, F. A. (1987): Reproductive effort in plants. I. Carbon allocation to reproduction. - American Naturalist 129: 876-896.

[25] Reynolds, J. F., Thornley, J. H. M. (1982): A shoot: root partitioning model. - Annals of Botany 49: 585-597.

[26] Sadras, V. O., Egli, D. B. (2008): Seed size variation in grain crops: allometric relationships between rate and duration of seed growth. - Crop Science 48: 408-416.

[27] Samson, D. A., Werk, K. S. (1986): Size-dependent effects in the analysis of reproductive effort in plants. - American Naturalist 127: 667-680.

[28] Sugiyama, S., Bazzaz, F. A. (1998): Size dependence of reproductive allocation: the influence of resource availability, competition and genetic identity. - Functional Ecology 12: $280-288$.

[29] Wang, X., Taub, D. R. (2010): Interactive effects of elevated carbon dioxide and environmental stresses on root mass fraction in plants: a meta-analytical synthesis using pairwise techniques. - Oecologia 163: 1-11.

[30] Weiner, J., Thomas, S. C. (1992): Competition and allometry in three species of annual plants. - Ecology 73: 648-656.

[31] Weiner, J. (2004): Allocation, plasticity and allometry in plants. - Perspectives in Plant Ecology, Evolution and Systematics 6: 207-215.

[32] Weiner, J., Campbell, L. G., Pino, J., Echarte, L. (2009): The allometry of reproduction within plant populations. - Journal of Ecology 97: 1220-1233.

[33] Westoby, M., Wright, I. J. (2003): The leaf size - twig size spectrum and its relationship to other important spectra of variation among species. - Oecologia 135: 621-628.

[34] Yang, Y., Fang, J., Ma, W., Guo, D., Mohammat, A. (2010): Large-scale pattern of biomass partitioning across China's grasslands. - Global Ecology and Biogeography 19: 268-277.

[35] Yang, Y., Luo, Y. (2011): Isometric biomass partitioning pattern in forest ecosystems: evidence from temporal observations during stand development. - Journal of Ecology 99: 431-437. 